
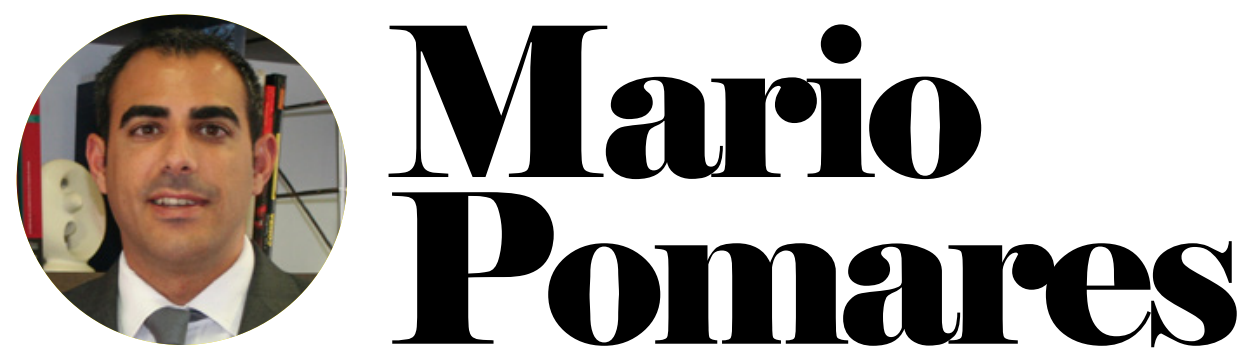

Profesor de Ciencia Jurídica de la Universidad Miguel Hernández

\title{
La Denominación de Origen garantiza la calidad de la Granada Mollar de Elche y la defiende frente a terceros
}

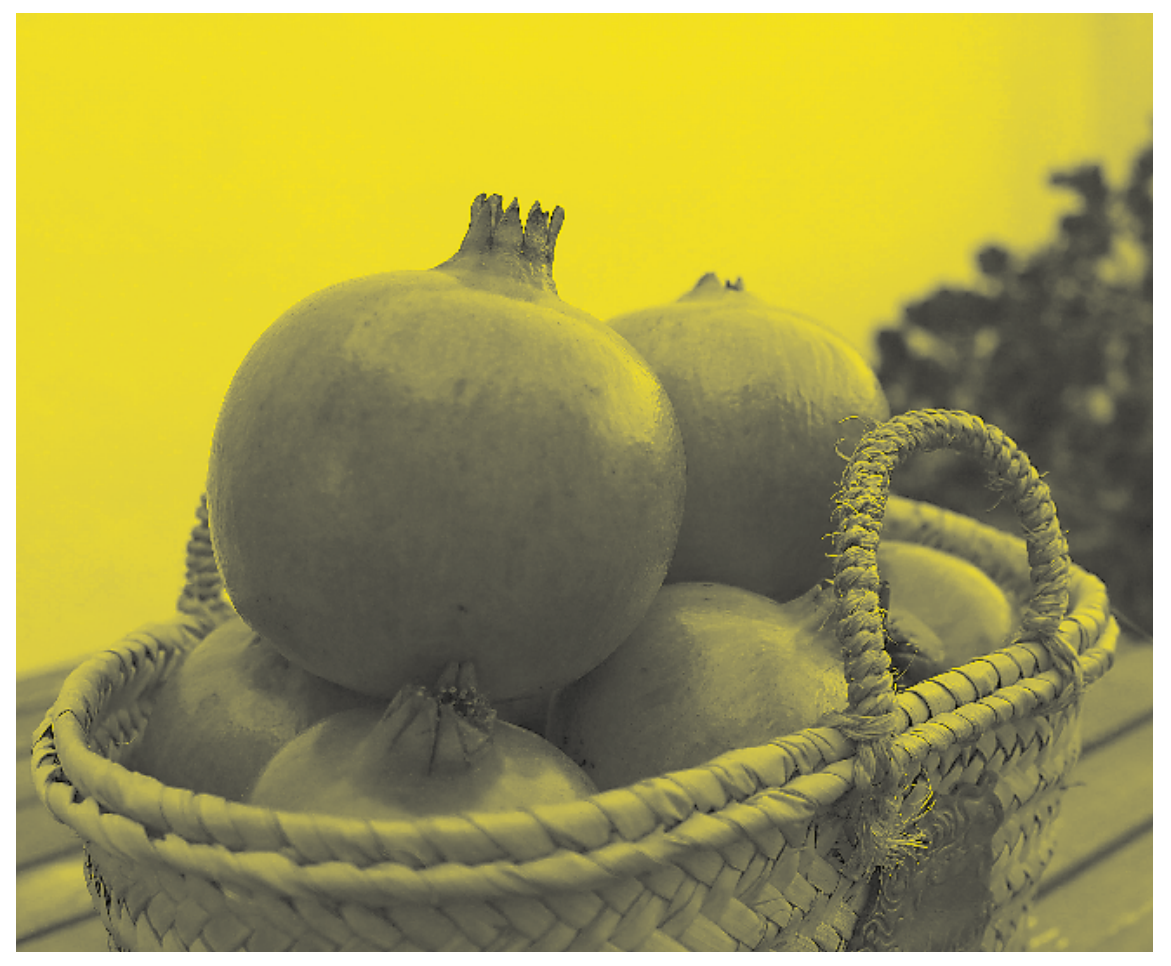
sus colores, que van desde el crema hasta el rojo intenso. El pasado mes de enero, la Comisión Europea otorgó la concesión de la Denominación de Origen Granada Mollar de Elche, un sello que protege y garantiza la calidad de esta variedad autóctona de las zonas del Bajo Vinalopó, L'Alacantí y el Bajo Segura. Son numerosos los productos agroalimentarios españoles que han optado por diferenciarse en función de la calidad y la reputación que aportan los lugares donde se producen, transforman o elaboran. En 2012, había registradas 168 denominaciones de origen en España, correspondientes a 16 sectores agroalimentarios, según el Ministerio de Agricultura, Alimentación y Medio Ambiente. 

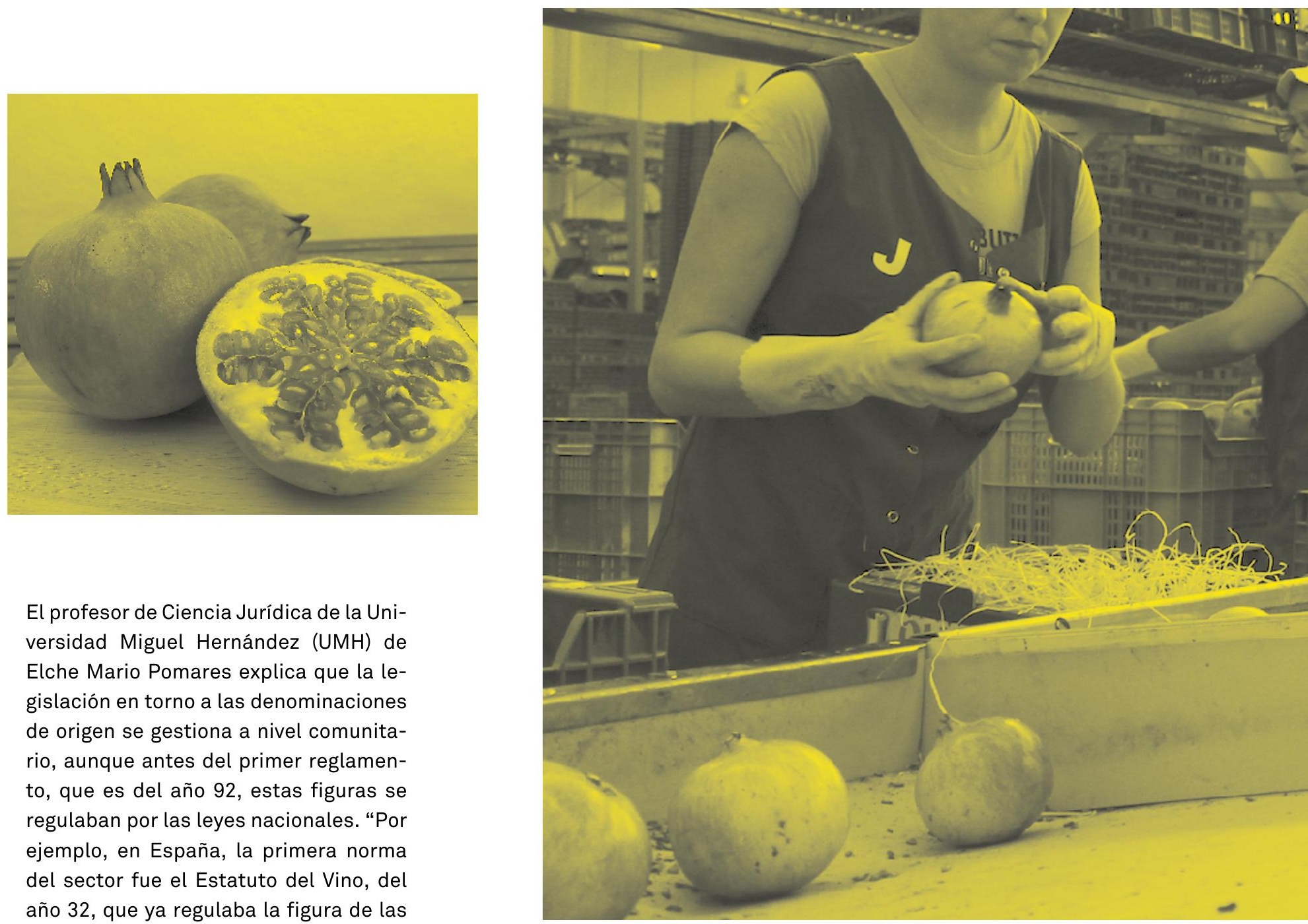

El profesor de Ciencia Jurídica de la Universidad Miguel Hernández (UMH) de Elche Mario Pomares explica que la legislación en torno a las denominaciones de origen se gestiona a nivel comunitario, aunque antes del primer reglamento, que es del año 92, estas figuras se regulaban por las leyes nacionales. "Por ejemplo, en España, la primera norma del sector fue el Estatuto del Vino, del año 32 , que ya regulaba la figura de las denominaciones de origen de estos productos", matiza.

Existen cuatro reglamentos comunitarios sobre las denominaciones de origen: el de los productos agrícolas y alimenticios; el que ampara a los vinos; otro aplicable a los vinos aromatizados y el reglamento de bebidas espirituosas. El reciente registro de la Granada de Elche empezó, como en el resto de casos, a través de una solicitud promovida por el grupo de productores interesados en obtener la protección. La petición fue tramitada a través de la Consejería de Agricultura, Medio Ambiente, Cambio Climático y Desarrollo Rural. Y, tras la decisión favorable de la Comunidad Autónoma, se inició su tramitación a la Dirección General de Agricultura de la Comisión Europea, órgano encargado de otorgar el sello.

"Mientras que se está tramitando y llega la resolución por parte de Bruselas, el Estado Miembro puede otorgar una protección nacional transitoria que tiene vigencia en España, que es lo que ha ocu- rrido en el caso de la Granada Mollar de Elche", explica el profesor. Quien añade que, para el presente año, cuando empiece la próxima campaña de recogida de la Granada, entre septiembre y octubre, ya se comercializará con el sello característico de la denominación de origen.

Cada denominación de origen tiene sus particularidades. En el pliego de condiciones de la Granada de Elche se establecen las características tanto morfológicas (redonda, dividida en varios lóbulos, corteza fina, lisa y brillante); físico-químicas (porcentaje de acidez mínimo de 0,18 y máximo de 0,24,
Comercializadores y productores deben cumplir obligaciones y someterse a inspecciones dad...). Es decir, el pliego determina los procesos de producción, elaboración y recolección. "Las condiciones que se detallen deberán cumplirse en todos los productos que deseen ser etiquetados con el sello", subraya Mario Pomares.

Como explica el letrado, la denominación de origen constituye un bien de titularidad pública, ni siquiera es propiedad de la asociación de productores, encargada de la gestión. En la Comunidad Valenciana, la primera denominación obtenida fue la del Turrón de Jijona, a la que también asesora el despacho "Berenguer y Pomares Abogados" que mínimo 14 grados Brix y con un índice de madurez entre 60 y 90), como organolépticas (la pulpa del fruto es astringente y de sabor muy dulce, frutos sanos, de aspecto fresco, exentos de hume- dirige el profesor de la UMH y que puede presumir de contar con una vasta y diversa experiencia en el asesoramiento jurídico en el ámbito de las denominaciones de origen. Su labor en este campo es 
